\title{
À GUISA DE APRESENTAÇÃO: POR UMA FENOMENOLOGIA DA DIFERENÇA
}

Em Entre o passado e o futuro, Hannah Arendt afirma: "a educação tem a ver com o nascimento, com o fato de que constantemente nascem seres humanos no mundo". ${ }^{1}$ A cada nascimento fazemos a experiência de nos depararmos diante de um outro, uma alteridade, um diferente, um não-igual. $\mathrm{O}$ nascimento permite-nos renovar reafirmando um princípio basilar de nossa organização social. Trata-se do princípio de identidade no qual nos filiamos para vivermos juntos, entre iguais. Esse mesmo princípio permite-nos reconhecer o diferente, o não igual a nós, o estrangeiro. A cada nascimento, esta alteridade que vem ao mundo é marcada pela diferença: não fala, não ouve e não enxerga como nós; não pensa como nós e não é regido pelos valores e etiquetas aos quais acordamos em viver; não tem o mesmo padrão de comportamento de nós. Trata-se de um outro, um não-eu, um ser que nos escapa segundo a segundo: é um estranho entre nós. O nascimento trás ao mundo uma novidade da qual nada sabemos de seu passado, nos assustamos em seu presente e, mas que desejamos arduamente saber de seu futuro. Por ser portadora da novidade, o nascimento permite que venha ao mundo essa alteridade, esse diferente, esse não-ser. Essa novidade, esse diferente, esse não-igual que passa a habitar entre os iguais tem um alto poder desestabilizador de nossa geometria social, de nosso princípio de identidade, de nosso modus vivendi. A afirmação de Hannah Arendt é absolutamente visceral: temos que nos haver com cada ser que vem ao mundo através do nascimento. Temos que educar cada alteridade que, pelo nascimento, passa a habitar entre os iguais. Nessa mesma obra, continua a filósofa:

A educação está entre as atividades mais elementares e necessárias da sociedade humana, que jamais permanece tal qual é, porém se renova continuamente através do nascimento, da vinda de novos seres humanos. Esses recém-chegados, além disso, não se acham acabados, mas em um estado de vir a ser. Assim, a criança, objeto da educação, possui para o educador um duplo aspecto: é nova em um mundo que lhe é estranho e se encontra em processo de formação; é

1 ARENDT, Hannah. Entre o passado e o futuro. São Paulo: Perspectiva, 2000. p. 223. 
um novo ser humano e é um ser humano em formação. ${ }^{2}$

Educar a novidade, educar esse outro; formar o igual no diferente, instituir o ser no não-ser, instituir o princípio de identidade na diferença, nacionalizar o estrangeiro. Essa não é somente a tarefa da educação, mas, também, das políticas, da economia, o direito, da medicina, da psicologia e da sociologia.

Os discursos e narrativas sobre o diferente, o estrangeiro, o de hábitos estranhos, sobre aquele que não é um igual, a nós esteve presente em toda a historicidade e em diversas culturas. Trata-se da narrativa sobre a alteridade e sobre o drama existencial de se estar num não-lugar, reflexo de seu nãoser. O diferente não está no mundo da política porque o seu ser é diferente de todo ser, de toda normalidade, de toda massa: é um não-ser que, pela negatividade, escapa das políticas destinadas a maioria. Vejamos algumas narrativas dramáticas.

Édipo é um estrangeiro; é um enigma para si mesmo. Em busca de si mesmo, da revelação de sua própria existência, Édipo sai de Corinto e dirige-se para Tebas. No caminho, mata um homem de nome Laio. Ao chegar aos portões de Tebas, depara-se com a Esfinge. Ao desvendar o enigma da Esfinge, destrói-a. Como prêmio, torna-se rei de Tebas e casar-se com Jocastra, a rainha viúva. Da união com Édipo, Jocastra gera duas filhas. Édipo desfruta das minúcias de rei de Tebas. Quando todo o enigma de sua existência é revelado pelo sábio cego Tirésias, a verdade de sua existência lhe é revelada, tal qual havia sido pronunciado pelo Oráculo de Delfos: Édipo matara o pai e desposara a mãe. Cometeu, então, os dois piores crimes: parricídio e incesto. Como rei e criminoso, é Édipo quem deve designar a punição a si mesmo: exílio. A punição de Édipo é tornar-se um estrangeiro, um sem pátria, um ser sem pertencimento, sem ligação, sem cultura, sem terra. A estrangereidade remete ao não pertencimento a nenhum grupo, ao isolamento de todos, a ser diferente. O estrangeiro não pertence a polis, sua linguagem, sua cultura e hábitos são distintos dos outros. O estrangeiro é o outro, aquele que não pertence ao grupo e que, portanto, relega-se às margens da vida política. Ao exilar-se e ser um estrangeiro, a única dignidade que lhe cabe e a única coisa que busca em sua vida já funesta, é um lugar

\footnotetext{
2 Ibidem, p. $234-235$.
} 
para que seu corpo seja enterrado quando morrer.

Quasímodo é um estranho. É um sujeito de hábitos e de aparência física estranha. Faz parte de um grupo de diversidade que choca pela diferença visível e explícita. Quasímodo é corcunda, coxo, com uma saliência protuberante acima dos olhos, descrita por Vitor Hugo como uma grande verruga, e de fala ininteligível. A estranheza de Quasímodo poderia e de fato assustaria as pessoas pertencentes ao grande grupo de normais. Temido pelos habitantes, precisava, assim, ser escondido, estar a margem e longe da vista das pessoas. É abandonado ainda criança e adotado pelo arcebispo Claude Frollo, que o esconde no campanário da Catedral de Notre Dame, dando-lhe a incumbência de tocas os sinos da catedral. Esta atividade acabou por deixá-lo surdo. Assim, Quasímodo é um defeituoso, um esquisito, um estranho, um diferente: não ouve, não fala direito e não se aparente como as pessoas normais. Trata-se de um monstro que deve ser excluído. Quasímodo é o paradigma daquilo que Foucault chamou, em Os anormais, de monstruosidade como uma tipologia dos anormais. Ao sujeito estranho, marcado pela sua monstruosidade física e diferente dos outros, é designado ou o subterrâneo dos hospitais, manicômios e casas, escondendo-o, na penumbra e no silêncio, dos outros olhares e julgamentos, ou a exposição nos carnavais e picadeiro de circos nos conhecidos freak show, num movimento de lançar luz no monstro, publicizando a sua diferença, chocando a sociedade com as aberrações. Esconder e silenciar ou expor e divertir-se ridicuralizando o monstro. Eram esses os destinos dos estranhos, dos monstros, do diferente. E este foi o destino de Quasímodo: escondido e silenciado pelo arcebispo Frollo, exposto e ridicuralizado quando aparece ao público.

Doutor Jekyll é um louco. Henry Jekyll, o médico que faz experiência consigo mesmo, tem sua personalidade fraturada. Trata-se de um eu cindido, divido numa dualidade diurna e noturna; boa e má; racional e impulsiva; ética e criminosa; pacífica e violenta; controlada e excessiva; apolínia e dionisíaca. Dr. Jekyll quer explorar os subterfúgios e limites da consciência, num movimento de expansão do eu para além do eu, rumo ao não-eu - ao desconhecimento de si mesmo. De posse dos paradigmas da ciência e do método experimental, Dr. Jekyll cria a fórmula a fim de expandir a própria consciência para além daquilo que ela sabe de si mesma. Ao experimentar a fórmula descobre, em si mesmo, em sua própria consciência o Sr. Hyde: o monstro violento e taciturno, marcado pela desmedida nas ações rumos aos fins desejados. Sr. Hyde habita 
a consciência do Dr. Jekyll; é o outro eu no eu; é o estranho, o esquisito, o diferente que habita o Dr. Jekyll, médico gentil e socialmente referendado. $\mathrm{O}$ assustador da experiência levada a cabo pelo Dr. Jekyll é que revela uma realidade que, segundo ele, é universal aos homens: o bem e o mal coabitam o mesmo ser. Dessa forma, o homem é essa tensionalidade disfuncional que não se encaixa num mundo homogêneo e uniforme.

Estes são três exemplos de narrativas em torno do diferente, daquele sujeito que difere da massa, do padrão de normalidade, do usual. A diferença sempre emergiu como um problema capital para as formas de organização social e para a vida política, exatamente porque rompe com a uniformidade e instaura um problema de grande monta: trás à luz, expondo a todos os olhares, os limites da nossa arquitetura social. O mundo foi construído pelo sujeito normal para a vivência de sujeitos normais. É assim que os caminhos são feitos para pessoas que andam sob duas pernas; que as placas de sinalização são feitas para pessoas que enxergam com propriedade; que os lugares de convivência social são construídos e organizados para pessoas centradas racionalmente e que a comunicação é feita através de tecnologias para pessoas ouvintes. $\mathrm{O}$ mundo não foi construído pensando no monstro, no estrangeiro, no deficiente de todo tipo. Eles, de fato, operam o descentramento das formas de organização social construídas pelos sujeitos normais. Coerente com a ditadura da normalidade, exclui-se o diferente, relegando-o ao submundo social.

É na contemporaneidade que esses sujeitos marcados pela diferenças ganham espaço no aparato escolar. Esta é a era da multiplicidade de sujeitos educativos. Desde a Grécia clássica, o antropos educativo seguiu um ideal: a educação objetiva formar o sujeito racional (dualismo mente/corpo), masculino, dotado de uma substancialidade/essencialidade. A filosofia da educação refletiu e teorizou sobre as técnicas formativas desse modelo ideal de sujeito que, além dessas características é, também, centrado política e culturalmente. Na contemporaneidade, novos sujeitos educativos emergem no campo das teorias educacionais. Aqui surgem as mulheres, os deficientes, os doentes, os loucos e os pertencentes as minorias étnicas, sexuais e culturais aparecem enquanto fenômenos reais com os quais a educação tem que se haver. Não se trata de educar somente o sujeito masculino, racional, europeizado, sadio físico e mentalmente, mas toda uma gama de sujeitos até então esquecidos e excluídos das reflexões sobre a educação: 
A criança, a mulher, o deficiente, o estrangeiro romperam esse invólucro ideológico da pedagogia, mas também a sua unidade-unicidade, fazendo aparecer sujeitos diferenciados e teorias diversificadas, por interesses-guias, por estruturas ideais, por objetivos estratégicos que vieram a caracterizá-las. ${ }^{3}$

A escola passa a ser também o espaço de formação do diferente, do louco, do monstro, do estrangeiro. Emerge uma escola para a formação do anormal, enquanto um vocábulo utilizado

para designar esses cada vez mais variados e numerosos grupos que a Modernidade vem, incansável e incessantemente, inventando e multiplicando: os sindrômicos, deficientes, monstros e psicopatas (em todas as suas variadas tipologias), os surdos, os cegos, os aleijados, os rebeldes, os pouco inteligentes, os estranhos, os GLS, os 'outros', os miseráveis, o refugo enfim. ${ }^{4}$

Trata-se de um período de complexização do campo educacional, com o qual a filosofia da educação torna-se insuficiente para construir uma reflexão sobre tal diversidade antropológica. Ganha espaço, então, as outras ciências que, junto a pedagogia, lançam luz sobre esses novos sujeitos educativos, revisando as antigas teorias e reorganizando os espaços escolares, as metodologias de ensino/aprendizagem e as didáticas. Diante desses novos sujeitos educativos, a medicina, a psiquiatria, a biologia, a psicologia, a antropologia, a sociologia contribuem decisivamente para a pedagogia encontrar possíveis respostas diante do desafio de educar esses novos sujeitos. Trata-se, em suma, de um horizonte absolutamente amplo, de uma organização escolar absolutamente distinta daquela até então conhecida. De fato, educar a mulher, educar o deficiente, educar o louco ou o culturalmente diverso requer novas reflexões, novas teorias, novas concepções de escola, de ensino, de aprendizagem, de desenvolvimento humano. Em suma, é na contemporaneidade que a educação teve que enfrentar a diversidade cultural,

3 CAMBI, Franco. História da pedagogia. São Paulo: Editora da Unesp, 1999. p. 386.

4 VEIGA-NETO, Alfredo. Incluir para excluir. In: LARROSA, Jorge; SKLIAR, Carlos. (Org.). Habitantes de babel: políticas e poéticas da diferença. Belo Horizonte: Autêntica, 2001. p. 105. 
sexual, física e mental do humano. Diversidade que trouxe, por sua vez, um campo profícuo para as pesquisas educativas, além de desafios ainda hoje presentes para os cientistas da educação e para as políticas públicas para a educação. Afinal, educar e construir um sistema educativo para um modelo ideal de homem é imensamente mais simples do que construir um sistema de ensino para tal diversidade de sujeitos educativos.

A escola que emerge no final da modernidade e início da contemporaneidade, sob a auspicia do Estado, conjuga em seu interior uma série de saberes - da Filosofia, da Medicina, da Biologia, do Direito, da Psicologia - sobre o educando, sobre o professor, sobre ensino e aprendizagem, estabelecendo padrões desejáveis de formação, de comportamento, de pensamento. Entra no espaço da escola moderna esses novos sujeitos educativos, no nosso caso em especial, o diferente, o deficiente de todo tipo, o monstro e o estrangeiro. Diante do diferente, a escola assume o papel de formação do diferente á luz de um ideal formativo. Trata-se, então, de uma escola que governa o diferente:

a escola moderna é o locus em que se dá de forma mais coesa, mais profunda e mais duradoura a conexão entre poder e saber na Modernidade [...] funcionando, assim, como uma máquina de governamentalização que consegue ser mais poderosa e ampla do que a prisão, o manicômio, o quartel, o hospital. Isso faz da escola um lugar privilegiado para se observar, por exemplo, tantos as transformações que já aconteceram quanto as que ainda estão acontecendo na lógica social. ${ }^{5}$

São pensados para o espaço escolar técnicas de ensino, modelos de aprendizagem. As formas de estudo, a definição clara dos conteúdos de ensino, o controle do tempo e das atividades das crianças, a rígida disciplina moral são concebidos pelos teóricos da educação como elementos imprescindíveis à boa formação. De fato, a instituição escolar, num movimento de universalização da formação indo ao encontro do diferente, cria técnicas comuns à educação de todos. Instaura-se na escola uma relação em que o professor, à luz da emergente ciência da educação e de posse das técnicas de ensino, forma o sujeito diferente à luz de um ideal de ser humano ci-

\footnotetext{
5 VEIGA-NETO, 2001, p. 109.
} 
vilizado e moralizado, que emancipa-se de seu estado natural pelo cultivo da razão esclarecida. Em última instância, levanta-se a bandeira do grande projeto da escola moderna: formar todos os sujeitos nos bons costumes e no exercício da razão para a vida social. Nesse sentido, as escolas "formam todas as jovens gerações e as conformam a modelos de normalidade e de eficiência/produtividade social, além de docilidade político-ideológica". ${ }^{6} \mathrm{~A}$ escola é o lugar do governo do outro: "entendido no sentido amplo de técnicas e procedimentos destinados a dirigir a conduta dos homens. Governo da criança, governo das almas ou das consciências, governo de uma casa, de um Estado ou de si mesmo". ${ }^{7}$ A escola aparece como uma instituição poderosa de adestramento, de disciplinamento e de governo das crianças. Uma poderosa engenharia de formação de sujeitos normalizados, de sujeitos governados a fim de produzir comportamentos desejáveis a assimiláveis ao padrão de normalidade. Trata-se da escola enquanto um espaço de formação (Bildung) de sujeitos civilizados.

É disso que trata este dossiê: de sujeitos que, em sua historicidade, foram marcados pela diferença, pela exclusão, pela governamentalidade. Aqui, este dossiê é sobre sujeitos marcados pela surdez e de tecnologias escolares destinados a estes sujeitos.

O dossiê Libras foi gestado no interior do Grupo de Estudos e Pesquisa Políticas e Práticas em Educação Especial e Inclusão Educacional (GEPEPES) coordenado pela professora doutora Lazara Cristina da Silva, também proponente e organizadora deste dossiê. O GEPEPES está vinculado ao Programa de Pós-Graduação em Educação da Universidade Federal de Uberlândia, que foi grande incentivador para a materialização desse dossiê. Além disso, remetemos o apoio a este dossiê do Centro de Ensino, Pesquisa, Extensão e Atendimento em Educação Especial (CEPAEIUFU).

O dossiê Libras agrega um conjunto de seis artigos, sendo dois artigos de pesquisadores vinculados a instituições estrangeiras e quatro artigos

${ }_{6}$ CAMBI, 1999, p. 202.

7 FOUCAULT, Michel. Resumo dos cursos do Collège de France (1970-1982). Rio de Janeiro: Jorge Zahar Editor, 1997. p. 101. 
de pesquisadores de diferentes regiões do Brasil. O dossiê Libras abre com o artigo A língua de sinais na formação de professores: experienciais no espirito santo e em minas gerais, de autoria dos professores Carlos Henrique Rodrigues e Lucyenne Matos da Costa Vieira Machado, oportunidade em que discutem o processo de reconhecimento e de difusão da Libras no Brasil e seu estabelecimento como disciplina obrigatória nos cursos de formação de professores. Para esse propósito, recorre a uma análise das experiência na Universidade Federal do Espírito Santo e de uma das Universidades Federais do estado de Minas Gerais. A partir dessa análise, o artigo aponta que independente da exígua carga horária e a despeito de qual seja o conteúdo explorado na disciplina, a Libras no ensino superior desencadeia um consistente processo de transformação social, política, cultural e acadêmica. Segue o dossiê o artigo Formação de professores de língua brasileira de sinais: reflexões sobre o impacto desta ação para a educação, de autoria das professoras Ana Claudia Balieiro Lodi e Cristina Broglia Feitosa de Lacerda, que objetiva problematizar aspectos envolvidos na formação de professores de Libras para os diferentes níveis de ensino e as tensões decorrentes para a educação de surdos/educação inclusiva. $\mathrm{O}$ artigo constata o pouco investimento na formação do pedagogo bilíngue, em contrapartida, grande esforço na formação de professores para atuação nos anos finais do ensino fundamental, médio e na educação superior, concluindo que a lógica predominante nas políticas atuais privilegia os princípios da educação inclusiva e não da educação bilíngue para surdos. O quarto artigo do dossiê tem por título Reflexión en torno a la aplicación de herramientas para operar sobre las lenguas y el caso de la lengua de senas uruguaya (LSU), de autoria do professor Leonardo Peluso Crespi. Neste artigo, o professor Leonardo faz referência a quatro ferramentas que se costuma usar para operar as línguas: os sistemas de escrita, as ferramentas de registro e gravação, as ferramentas de gramática e as ferramentas de tecnologias da informação e comunicação, dando, neste artigo, ênfase à ferramenta dos sistemas de escrita. O dossiê segue com o artigo Lecturas, enseñanza de lengua y desercion estudantil em sordos y universitarios, de autoria do professor Juan Andrés Larrinaga, que analisa a relação dos estudantes surdos e do estudantes universitarios ingresantes concernente à leitura de textos acadêmicos. Para o autor, esta análise mostra os processos de exclusão similares que ocorrem em ambos os grupos. $\mathrm{O}$ artigo seguinte tem por título Representações na literatura 
surda sobre modos de ser surdo, da professora Lodenir Becker Karnopp. Este artigo investiga representações sobre modos de ser surdo que circulam em narrativas produzidas em Língua Brasileira de Sinais (Libras), por acadêmicos do Curso de Letras - Libras, das turmas iniciadas em 2008. O dossiê fecha com o artigo de autoria das professoras Lazara Cristina da Silva, Marilda Moraes Garcia Bruno e Dulcéria Tartuci, intitulado A língua brasileira de sinais nas universidades públicas da região centro-oeste: dilemas, conquistas e horizontes. O artigo das professoras Lazara Cristina, Dulceria e Marilda Bruno, visa apresentar as condições em que ocorreram a inserção da Libras nas instituições públicas da região Centro Oeste brasileira, a sua operacionalização, à luz do Decreto n. 5.626/05, que regulamenta a inserção da Libras nos cursos de Licenciatura, mostrando que as primeiras iniciativas de implantação da disciplina Libras e sua oferta têm sido realizadas a partir do esforço de pessoas e unidades acadêmicas envolvidas com a educação de Surdos e o ensino de Libras. O artigo mostra também que modificações nessa realidade da oferta da libras somente ocorreram a partir de $2013 \mathrm{com}$ a implementação do Programa Viver sem Limites do Governo Federal. O dossiê apresenta, também, a resenha do livro Por uma gramática de Língua de Sinais, de autoria da professora Eliamar Godói, que mostra o pioneirismo desta obra em termos de descrição da Língua de Sinais Brasileira, esclarecendo sobre a origem da sigla Libras e a sua adoção pela comunidade surda em propagar esta sigla.

Queremos, por fim, remeter nosso profundo agradecimento às professoras Lazara Cristina da Silva e Ana Cláudia Balieiro Lodi, por levar adiante a organização desse dossiê e fazer votos de que este material publicado pela Revista Educação e Filosofia seja de profunda utilidade a todos os pesquisadores e interessados na temática da surdez e a Língua Brasileira de Sinais.

Márcio Danelon Diretor de Editoração da Revista Educação e Filosofia. 